\title{
Secular trends in energy expenditure data from the UK National Diet and Nutrition Survey: a public health perspective
}

\author{
M.C. Venables, S. Nicholson, C. Roberts, D. Collins and P. Page \\ MRC Elsie Widdowson Laboratory, 120 Fulbourn Road, Cambridge, CB1 9NL, UKNAtional.
}

The prevalence of overweight and obesity continues to show an upward trend, with rates of overweight and obesity in England reaching $66 \%$ for men and $57 \%$ for women ${ }^{(1)}$. More alarming is the increased prevalence in overweight and obesity in children ${ }^{(2)}$. Energy intake (EI) and energy expenditure (EE) are two equally important sides of the energy balance problem. The UK National Diet and Nutrition Survey Rolling Programme (NDNS RP) is a unique survey, in that it collects not only dietary data but also an objective measure of free living energy expenditure using doubly labelled water (DLW). It therefore provides an accurate measure of total energy expenditure (TEE) compared to most other surveys that rely on proxy measures. The aim of this study is therefore to evaluate whether secular trends exist in TEE in the UK over the six year period between 2008 and 2014.

TEE was estimated over a ten-day measurement period using the DLW method ${ }^{(3)}$. Data from 371 and 399 participants respectively, for years $1 \& 3$ (2008 \& 2010) and years $6 \& 7$ (2013 \& 2014) of the NDNS RP was used. The data was categorised by sex and age (Table 1).

Table 1. Weight and energy expenditure categorised by age and sex for the respective year groups.

\begin{tabular}{|c|c|c|c|c|c|c|c|c|c|}
\hline \multirow[b]{2}{*}{ Age group (y) } & \multirow[b]{2}{*}{ Sex } & \multicolumn{2}{|c|}{$\mathrm{N}$} & \multicolumn{2}{|c|}{ Weight (kg) } & \multicolumn{2}{|c|}{ BMI $\left(\mathrm{kg} / \mathrm{m}^{2}\right)$} & \multicolumn{2}{|c|}{ TEE (kcal) } \\
\hline & & $\overline{Y 1 \& 3}$ & $\bar{Y} 6 \& 7$ & Y1\&3 & Y6\&7 & Y1\&3 & Y6\&7 & Y1\&3 & Y6\&7 \\
\hline \multirow[t]{2}{*}{$4-10$} & Males & 41 & 33 & $26 \cdot 5$ & $26 \cdot 6$ & $16 \cdot 8$ & $16 \cdot 4$ & 1843 & 1862 \\
\hline & Females & 41 & 32 & $29 \cdot 4$ & $27 \cdot 4$ & $17 \cdot 3$ & $17 \cdot 1$ & 1763 & 1655 \\
\hline \multirow[t]{2}{*}{$11-15$} & Males & 34 & 42 & $52 \cdot 2$ & $53 \cdot 6$ & $20 \cdot 3$ & $20 \cdot 9$ & 2714 & 2705 \\
\hline & Females & 38 & 42 & $56 \cdot 3$ & $53 \cdot 2$ & $22 \cdot 4$ & $20 \cdot 5$ & 2379 & 2307 \\
\hline \multirow[t]{2}{*}{$16-49$} & Males & 38 & 51 & $85 \cdot 6$ & 80.6 & $27 \cdot 0$ & $25 \cdot 7$ & 3462 & $3231^{\mathrm{a}}$ \\
\hline & Females & 40 & 51 & $69 \cdot 4$ & $70 \cdot 5$ & $26 \cdot 2$ & $26 \cdot 2$ & 2530 & 2606 \\
\hline \multirow[t]{2}{*}{$50-64$} & Males & 41 & 42 & $86 \cdot 6$ & $86 \cdot 7$ & $27 \cdot 9$ & $28 \cdot 5$ & 3148 & 3074 \\
\hline & Females & 37 & 42 & $76 \cdot 7$ & $76 \cdot 3$ & $29 \cdot 6$ & $29 \cdot 1$ & 2432 & 2474 \\
\hline \multirow[t]{2}{*}{$65+$} & Males & 29 & 32 & $80 \cdot 0$ & $85 \cdot 4$ & $27 \cdot 4$ & $28 \cdot 5$ & 2661 & 2763 \\
\hline & Females & 32 & 32 & $74 \cdot 0$ & 73.0 & $28 \cdot 7$ & $28 \cdot 6$ & 2163 & 2212 \\
\hline
\end{tabular}

$\mathrm{a}=$ significantly different from $\mathrm{Y} 1 \& 3, \mathrm{P}<0.05$.

For the majority of age, sex categories, EE had not significantly altered over the six year time period. However, the 16-49 year old male group showed a $6.7 \%$ decrease in TEE (Table 1).

It would appear that over the short time period of six years, TEE has remained stable except for the 16-49 year old males in which it has decreased. This may be significant in the context of public health as EE and physical activity are two important drivers of energy balance and may influence the prevalence of overweight and obesity.

This work was jointly funded by Public Health England and the UK Food Standards Agency.

1. Fuller E, Mindell J \& Prior G (eds) (2017) Health Survey for England 2016, London: NHS Digital. Available at https://digital.nhs.uk/catalogue/ PUB30169 [accessed 26 March 2018].

2. National Child Measurement Programme - England, 2016-17 (2017). Available at https:/digital.nhs.uk/catalogue/PUB30113 [accessed 26 March, 2018].

3. Schoeller (1988) J Nutr 118, 1278-1289. 